\title{
Urban agriculture, dietary diversity and child health in a sample of Tanzanian town-folk
}

\author{
Natascha Wagner, Erasmus University Rotterdam \\ Luca Tasciotti, Department of Economics, SOAS University of London
}

\begin{abstract}
Under-nutrition and micronutrient deficiency continue to be two of the major health burdens in less developed economies. In this study, we explore the link between urban agriculture, dietary diversity and child health, using weight-for-age and height-for-age Z-scores.

The study makes use of two rounds of observational data for urban Tanzania and employs an instrumental variables estimation approach. We show that practising urban agriculture leads to the consumption of a greater variety of food items; the health status of urban children living in households practising urban agriculture significantly improves in the short-, and more importantly, in the long-term.
\end{abstract}




\section{Introduction}

The world is still struggling to achieve food security. Food price crises, political instability, climate change and economic shocks affect the food security of 850 million people mostly living in transitional and developing economies (FAO, 2014). Food consumption and micronutrient intake of these people, as well as the quality and diversity of their diets, still represent major challenges (Müller and Krawinkel, 2005). Especially for children, caloric deprivation, the lack of essential nutrients and the absence of dietary diversity contribute to the appearance of long lasting problems related to both physical and mental health, and lead to less economically productive populations (Black et al., 2003). The great majority approximately $80 \%$ - of under- and malnourished children are concentrated in 20 countries; despite isolated successes in specific countries and circumscribed areas, effective hungerreduction interventions and appropriate policies are failing to improve the nutrition of those children (Bryce et al., 2008).

The absence and the inadequate intake of basic nutrients compromise children's immune systems making them more susceptible to infection and disease. An insufficient supply of protein, carbohydrates and fat is the major cause of diarrhoea while iron deficiency leads to anaemia, and has the potential to impair infant motor and mental functions (Ronnenberg et al. 2004; Friel et al., 2003; Lozoff et al., 2003; Müller et al., 2003; GranthamMcGregor and Ani, 2001). Lack of iodine reduces the production of thyroid hormones and vitamin A deficiency also contributes to the occurrence of anaemia (Ambrus, 2004). Moreover, acute episodes of under-nutrition lead to weight loss resulting in low weight-forage (WAZ) or wasting; chronic or repeated exposure to under-nutrition or infections affects the growth of children in height leading to low height-for-age (HAZ) or stunting. Long-term consequences of malnutrition include impaired cognitive development. There is strong evidence that impaired growth is associated with poor school performance and reduced intellectual capacity with long lasting consequences for the individual and the society as a whole (De Onis and Blössner, 2003; Glewwe et al., 2001; Glewwe and King, 2001; Mendez and Adair, 1999). A number of studies have demonstrated the association between anthropometric deficits and mortality and the contribution of malnutrition to child mortality is now widely accepted (Liu et al., 2015). 
In this article, we assess one channel for improved nutrition and dietary diversity among town dwellers, namely urban agriculture. Urban dwellers practising agricultural activities may increase the dietary diversity of their household members as urban agriculture translates into having more ready access to dairy products, meat, fresh fruits and vegetables. We focus on children living in urban areas of Tanzania; while households in rural areas are often subsistence farmers and do not have any alternative income generating activity, urban households are also engaged in activities different from agriculture which allows us to derive the impact of urban agriculture on dietary diversity and child health while controlling for other sources of income.

Over the past couple of decades, urban agriculture has increasingly gained recognition as a viable intervention strategy for urban households to improve their nutritional status, to have access to fresher food and as an additional source of income; it also allows poorer households to reduce their food budget shares. Exploring the effects of urban agriculture is a non-negligible challenge for local governments, development advisors and humanitarian organizations, particularly in the light of the urbanization process, which has significantly increased food insecurity in urban areas (Djurfeldt, 2015; Ravallion et al., 2007; Drechsel and Kunze, 2001). The African continent in general and Tanzania in particular are undergoing a rapid urbanization process with an increase of about $37 \%$ in the urban population in SubSaharan Africa as a whole and a 50\% increase in Tanzania in the last two decades (Crush and Frayne, 2011). Yet the issue of urban food security has long been neglected. In fact, the complexity of urban food security along with malnutrition among urban populations has been addressed by fostering the development of rural smallholders rather than concentrating on urban solutions, which could have avoided the food and bread riots that occurred in several African cities (Armar-Klemesu, 2001). Urban agricultural activities have been shown to represent a valid, reliable and cost-effective food supply system for urban residents, especially for perishable vegetables and animal products (Bryld, 2003; Potutan et al., 2000). Although the positive contributions of urban agriculture have recently been highlighted, statistical evidence is still scant and limited to a few countries or regions within a country. Statistical analyses on the link between child health and household nutrition on one side and urban agriculture on the other have not been pursued yet. This article presents a first attempt to assess the existence and the magnitude of this nexus. We demonstrate that children who live in households practising urban agriculture have access to a more varied diet and are 
significantly better off as manifested in improved weight and height-for-age. Most of the impact stems from better access to dairy products and more meat, fish and eggs in their diet.

The remainder of this article is organized as follows; Section 2 presents a brief literature review. Section 3 introduces the dataset and descriptive statistics, Section 4 the methodological approach. Results are discussed in Section 5 and section 6 concludes.

\section{Urban agriculture and measures of child health: what does the literature say?}

Although the livelihood concept was initially developed in relation to the living conditions of rural households, it is currently widely accepted to apply it to urban scenarios as well (Rakodi and Lloyds-Jones, 2002). Urban households, just like their counterparts living in rural areas, seek to mobilize resources and opportunities and to combine these into a livelihood strategy (Rakodi, 2002; Owuor and Foeken, 2006). A number of broad 'strategies' can be discerned, with one of them being represented by urban farming (Potts, 1997).

Urban agriculture constitutes an important aspect in the process of income diversification and represents a phenomenon which has considerably expanded in the past three decades (Pellegrini and Tasciotti, 2014). Its growth in several developing countries across Africa, South-East Asia and Latin America since the late 1980s is largely understood as a response to escalating poverty, mass urbanization, volatile food prices and unexpected food shortages that have been exacerbated as a direct consequence of structural adjustment policies widely adopted in those years (Mougeot, 2005).

The importance and the extent of the urban agriculture phenomenon did not translate into concrete efforts to measure the number of people involved in it and, to date, statistics on the share/number of urban dwellers engaged in urban agriculture are limited and prone to inaccuracies. Estimates suggest that the share of households engaged in urban agriculture is large - up to as much as $40 \%$ of urban dwellers in Africa (Shackleton et al., 2009) and 50\% in Latin America (van Veenhuizen, 2006). Circumscribed studies indicate that $80 \%$ of the urban population living in Brazzaville, Congo engage in urban agriculture, $68 \%$ in the five biggest Tanzanian cities and 45\% in Lusaka, Zambia (Shackleton et al., 2009). A study using household level data from 15 less developed economies and those in transition points out that the share of households earning income from urban agriculture varies from a minimum of $11 \%$ in Indonesia to a maximum of $70 \%$ in Vietnam and Nicaragua (Zezza and Tasciotti, 2010). In the sample considered here, $18.59 \%$ of the households living in Tanzanian cities practise urban agriculture with this percentage increasing for the lower income strata of the 
population, which already gives an idea of the urban agriculture-poverty nexus. The success of urban agriculture in terms of the number of households involved clashes with a major constraint which is access to available land; farmers frequently do not own the land they farm but rather they use public spaces or privately owned vacant lots, with or without the owners' permission. The low tenure security and questionable legality of urban agriculture negatively affects its efficiency, prevents technological improvements and the implementation of official projects (Djurfeldt, 2015).

The effects urban agriculture is supposed to have are diverse and depend on a number of characteristics related to the farming activity: size of the plot, number of crops, distance of the plot from the dwelling, number of farmers working on the plot, etc. Generally speaking, in the absence of formal employment opportunities in the industrial and service sectors, practising agriculture constitutes a sine-qua-non condition for the households' livelihoods (World Bank, 2007; Ellis and Sumberg, 1998).

Practising urban agriculture can be seen as a way to counterbalance the negative effects of food price crises, food price increases, droughts and other contextual factors that directly and indirectly affect the nutrition of households (FAO, 2014; Maltsoglou et al, 2010). Furthermore, the diet of urban households relies mainly on what is available for purchase in the market, whereas rural dwellers often produce their own food (Mbaye and Moustier, 2000; Moustier and Danso, 2006). Transport difficulties between rural and urban areas may limit the food availability in urban markets; more perishable food items might not always be available for purchase and high prices of perishable goods may be prohibitive for poorer households (Maxwell et al., 1998). Practising urban agriculture can also generate income from the sale of some of the harvested products.

Studies to date have shown that urban agriculture greatly contributes to household food and nutritional security (Nugent, 2000; Brock and Foeken, 2006). While these studies either based on anecdotal evidence, on descriptive statistics or multivariate analysis - agree on the fact that practising urban agriculture is beneficial for the nutrition of the urban farmers and for their health, little is known about the consequences urban agriculture has on child health. Despite the fact that a connection between urban agriculture, dietary diversity and child health seems logical, the number of studies - either theoretical or empirical - measuring such a nexus is extremely scant to be generous. Dietary diversity has been recognized by nutritionists as being the key element for quality diets (UNICEF, 2010; Arimond and Ruel, 2004; Ruel, 2003): increasing the variety of foods across and within food groups has been 
globally recommended by nutritionists as it guarantees an adequate intake of a wide range of nutrients. Much of the existing literature has focused on the relation between dietary intake and diversity, and the nutritional status on one side and the risk of mortality and the occurrence of several diseases on the other (Kant et al., 1995). Concurrently, a relationship between dietary diversity and the body mass index has been established for adult women in Burkina Faso (Savy et al., 2006).

Malnutrition and lack of dietary diversity represents a particularly severe problem among poor children living in less developed areas of the world, where nutrition is predominantly based on starches, seasonal fruits and vegetables, and few or no animal products (compare review by Kant, 1996). For infants and young children, the malnutrition/dietary diversity problem is particularly critical as they need energy - and hence food - to grow physically and mentally (Arimond and Ruel, 2002; Onyango et al., 1998; Taren and Chen, 1993). A growing body of the literature indicates that growth lost in the early years of life is only marginally regained during childhood and adolescence. The effects of malnutrition are noticeable from the weight- and height-for-age scores which indicate how a group of children in a given country performs in terms of weight and height compared with those of the same age and living in a well-nourished reference population (World Health Organization, 1995). Malnutrition affects not only the physical development of children as their cognitive capacities may be affected too; malnourished children are found to score poorly on cognitive function tests and have poorer psychomotor skills. Lastly, malnutrition may have lasting consequences due to the intergenerational transmission of poor nutrition and anthropometric status (Alderman et al., 2004).

The importance of this study is twofold; on the one hand it tries to measure the existence and the extent of urban agriculture and its contribution to dietary diversity. It is estimated that $38 \%$ of the population living in developing countries currently live in urban areas (Ruel at al., 1998). The expansion of the cities will affect all aspects of food supply, the way food will be distributed and the geography of poverty (Garrett and Ruel, 2003). Secondly the study assesses the impact of dietary diversity on child health as measured by two indicators, the height- (HAZ) and weight-for-age Z-score (WAZ). Thus, the study links urban agriculture, dietary diversity and child health. 


\section{Opening the household survey box: What do the data say?}

We make use of the Tanzania National Panel Survey that gathers a wide range of household characteristics and activities such as demographic and socioeconomic factors, information on food consumption and income generating activities. The Tanzanian National Bureau of Statistics implemented the first two surveys in 2008-2009 and in 2010-2011. The dataset is representative at the national level. For the purpose of this article we consider exclusively urban households leaving out peri-urban households. The 2008-2009 sample consists of 3,265 households with 1,202 households in urban areas. The total sample size for the 2010-2011 survey is 3,924 with 1,295 urban households. Our estimation sample of urban households with children below the age of five for which we have full information on all outcome and control variables, consists of a total of 509 households; 203 households are from the 20082009 survey and 306 households from the 2010-2011 sample.

We apply the official definition of urban versus rural areas following the 2002 population and housing census. Tanzania's National Bureau of Statistics (NBS) relies on enumeration areas as primary sampling units; each enumeration area has a population of 300 to 900 individuals and is defined as urban, peri-urban or rural. The decision as to whether an enumeration area is urban, peri-urban or rural is made by the Region Census Committees. ${ }^{1}$ Having defined what we consider an urban area based on local statistics, we employ the definition of the Food and Agriculture Organization of the United Nations (FAO) for urban agriculture. Urban agriculture is defined as the practice of cultivating food and raising animals in or around a town or city (c.f. FAO, 2017). ${ }^{2}$

For our analysis this results in a sample of 509 urban households with 624 children below the age of five, for whom weight-for-age information is available; height-for-age information is available for 598 children. In what follows, we will define the different indicators and describe the link between household participation in urban agriculture, dietary diversity and child anthropometrics.

\section{Definition of urban agriculture, dietary diversity and child health}

In the context of this article, urban agriculture is defined as the growing of plants and the raising of animals in urban areas. We analyse only small-scale agriculture below 5 acres and

\footnotetext{
1 Urban areas have been defined relying on the Village and the Urban Ward Act, respectively written in 1975 and 1976. For the purpose of this study, we rely on this definition as the enumeration areas are considered to be the smallest spatial unit that respects politico-administrative entities and existing boundaries of regions/neighbourhoods (Muzzini and Lindeboom 2008).

${ }^{2}$ See the website of FAO: http://www.fao.org/urban-agriculture/en/ [Last accessed on January 16, 2017].
} 
only plots and farms located at a distance of less than 10 kilometres from the main dwelling are considered to be located within the urban perimeter. We apply the size restriction to avoid including any large industrial farms producing for the export markets which would bias our results.. The distance restriction ensures that our sample constitutes a de facto urban sample. For that reason we do not want to include households who consider themselves urban dwellers but report farming activities in distant rural areas. The average distance to the plot is 2.76 kilometres and the median distance is 2.00 kilometres. We define a plot as any piece of land that is declared by the household as being used for the cultivation of edible crops. Among those households with agricultural land average plot size is 1.87 acres and the smallest is 0.10 acres. For livestock activities, we want to make sure that we capture the asset value of the animals. Therefore, the household needs to report keeping at least one animal among cows, goats, and sheep or 10 fowls. Those households that report having livestock keep 3.64 animals on average. Based on the above definition of urban farming and livestock keeping, we construct an indicator variable equal to 1 for households that engage in urban agriculture and 0 otherwise; $18.59 \%$ of the children in our sample live in households that practise urban agriculture (Online Appendix, Table A1).

To capture dietary diversity we rely on the dietary diversity indicator established by nutritionists as a proxy of high quality diets (Arimond and Ruel, 2004). Dietary diversity is defined as the number of different foods or food groups consumed in the household over a given reference period, which is seven days in our case. Information about household consumption comes from the head or his spouse. We then create five food groups: (i) milk/dairy products, (ii) meat/fish/eggs, (iii) fruit/vegetables, rice/grain/tubers/cassava/pulses, (v) sugar/coffee/ alcohol/beverages. These five categories are derived from the classification of USAID (FANTA, 2006), which categorizes food into as many as 12 different groups. The category which includes sugar/coffee/alcohol/beverages will be used in the analysis that follows as a robustness check, as we do not expect to find any significant relation between the food items in this category and child health. The reason lies in the fact that urban farmers do not directly produce sugar, coffee, beverages and alcohol; hence urban agriculture does not constitute a channel through which access to those food products can be increased. Moreover, medical research has provided ample evidence that these food items might have negative effects on child health. Section 5 of this study will highlight this finding. 
To assess child health we rely on anthropometric measures, which are expressed in terms of standard deviations (Z-scores) from the median height or weight of children of the same age in a well-nourished reference population. ${ }^{3}$ Z-scores are comparable across different age groups, households and places and can be easily interpreted: a child with a Z-score of zero is of similar constitution as the reference population, while a negative Z-score indicates that the child is below average compared to those children in the reference population. The weightfor-age Z-score (WAZ) is a widely accepted short-term measure of malnutrition picking up transitory shocks such as lack of a varied diet due to a period of drought. The long-term accumulation of malnutrition and indications of stunting, in turn, are captured by the heightfor-age Z-score (HAZ). Existing evidence suggests a dynamic link between HAZ and WAZ that captures the process of child growth (Wagner and Rieger, 2015). Here we establish the link between the Z-scores, dietary diversity and urban agriculture.

\section{Descriptive statistics}

$18.59 \%$ of the households engage in agricultural activities. Moreover, Figure 1 shows that as many as $42 \%$ of the households in the lowest expenditure quintile practise urban agriculture with this percentage decreasing with rising household income. This trend suggests that urban agriculture may be seen as a coping strategy by the poorer households.

$<$ Figure 1 about here $>$

Turning to the dietary diversity indicator, out of the 59 possible food items a given household can report, consumption of a maximum of 40 items has been recorded; the average urban household consumes 19.60 different items (Online Appendix, Table A1). Considering the division of food items into food subgroups, it becomes clear that households rely mainly on agricultural staples from the group of rice, grain, tubers, cassava and pulses where an average variety of 8.75 out of a maximum of 18 is reached. Consumption of meat/fish/eggs is limited to roughly 2 different food items within seven days and the variety of fruits/vegetables consumed numbers 3.10 on average. The households are least likely to consume milk and dairy products in their weekly diet. This is a particularly important result since milk products constitute important elements of everyone's diet but especially for young children. Put differently, the diets of urban households rely heavily on staple foods since almost $50 \%$ of the

\footnotetext{
${ }^{3}$ The employed reference population is given by the WHO growth standards for breastfed children (de Onis, 2006).
} 
food items consumed are from the group of rice, grain, tubers, cassava and pulses. The second largest food group in the basket is sugar/coffee/alcohol/beverages (20\%), followed by fruits/vegetables (15\%). The groups of meat/fish/eggs/dairy products together account for only $14 \%$.

We now turn to the children and their health status (Online Appendix, Table A1), which constitute the outcome of interest in our analysis of urban agriculture working through dietary diversity to improve child health. Children in urban Tanzania are on average worse off compared with the international reference population, as the average WAZ is -0.57 indicating that children are wasted; the average HAZ is even lower, 1.07, implying stunting. This suggests that the short-term underweight experienced by the majority of these children is accumulated, resulting in considerably lower heightfor-age in the long run. In terms of other child characteristics, the sample taken into consideration is roughly gender balanced, the children are on average 2.4 years old and the mothers of the children under study are almost 30 years old. We further disaggregated the child-related statistics by expenditure quintiles highlighting that children in the lowest quintile have an average WAZ (HAZ) of -0.922 (-1.322) whereas children in the highest quintile are much better off as indicated by the average WAZ (HAZ) of -0.144 (-.784). Similarly, dietary diversity is lowest for the poorest households. In turn, the children living in the richest households enjoy the highest dietary diversity. Concerning the three middle wealth quintiles, children living in these households have fairly similar HAZ and WAZ scores. Yet, the scores are considerably higher than in the lowest expenditure group and considerably lower than in the highest expenditure group. Across expenditure groups, children living in households that practise urban agriculture tend to be better off on average.

\section{Methodological approach: The impact of dietary diversity on child health}

This section introduces the identification strategy for the link between urban agriculture and dietary diversity on the one hand and child health indicators on the other. Our empirical strategy derives from the conceptual framework developed by UNICEF, which summarizes the causes and consequences of child malnutrition (UNICEF, 2010). Three main factors affecting children's food intake are identified at the household level: (i) food availability, (ii) household behaviour - including childcare and choices of food acquisition - and (iii) intrahousehold allocation of goods. We apply this model to the urban context. We argue that food 
availability and consumption behaviour of urban households is a function of the economic situation of the household, which is not only captured by the expenditure group in which a household is placed but also influenced by the activities a household chooses to engage in. As one such activity we singled out urban agriculture. Based on a previous study that demonstrated that urban agriculture plays an important role in increasing the dietary diversity of the households practising it (Tasciotti and Wagner, 2015), we estimate the following relationship between dietary diversity Food $_{i}$ and urban agriculture Urban_Agri $i_{i}$ for every child $i$ :

$$
\text { Food }_{i}=b_{0}+b_{1} \text { Urban_Agri } i+b_{2} \text { Control }_{i}+\varepsilon_{i t}
$$

Since the conceptual model views activities such as urban agriculture as input into food availability and ultimately food availability as input into child health production, we derive the estimate $\widehat{F o O d}_{i}$ from equation (1) and estimate child health Child_Health dietary diversity as follows:

$$
\text { Child_Health }{ }_{i}=a_{0}+a_{1} \widehat{\text { Food }}_{i}+a_{2} \text { Control }_{i}+e_{i}
$$

The variable 'Child_Health ${ }_{i}$ ' represents the weight- or height-for-age Z-score. The variable 'Food ${ }_{i}$ ' captures the dietary diversity measure (either a simple count of food items or a count of food items within each of the five food groups). The resulting two-stage (2SLS) model allows us to trace out the link between urban agriculture and dietary diversity in the first stage and in the second stage the link between dietary diversity and child health with the former accounting for urban agriculture. Thus, for the purpose of assessing the relationship between urban agriculture, dietary diversity and child health we need to rely on a two-stage model. Estimating only equation (2) separately does not allow us to account for the increase in available food due to urban agriculture. Moreover, based on the conceptual framework by UNICEF we decided to treat dietary decisions at the household level as endogenous since we are not able to account for all aspects affecting nutritional intake such as preferences and the intra-household allocation of goods (cf. UNICEF, 2010).

Methodologically the focus on urban households is the key for our identification strategy: Contrary to rural households, the urban households we analyse do not exclusively depend on agricultural activities and report being engaged in a variety of other income 
generating activities, such as being government employees, being self-employed in petty commerce and other manual work. When examining the main occupation of a child's parents, we can set up a two-stage model and use urban agricultural activities as an instrument for food intake. Put differently, in the sample at hand income does not exclusively depend on the agricultural activities. Therefore, we argue that a household's engagement in urban agriculture affects child health through its impact on dietary diversity. In fact, the child anthropometric indicators themselves are not significantly correlated with urban agriculture.

In addition, we look for a wide range of household level characteristics that have been identified by the literature as impacting on child health (Charlemaigne and Gauthier, 2009; Marmot et al., 2008). These elements are collected in the matrix 'Control ${ }_{i}$ '. We account for the following confounding factors: child characteristics including age and gender, household demographics such as family size, the share of children below the age of five, the share of women of working age, the time the household has been resident at the current place and an expenditure classification of the household in five quintiles, maternal characteristics such as age, marital status, level of education and occupation and paternal characteristics (age, level of education and occupation). Since we are interested in the impact of a diversified diet on child health we also take account of food processing (stove used to prepare the meals) and conservation (refrigerator ownership). ${ }^{4}$ The date of the survey is also accounted for. Standard errors are clustered at the neighbourhood level to allow for unobserved shocks within neighbourhoods.

Clearly the employed identification strategy is valid only if urban agriculture is a decisive predictor for dietary diversity that can be credibly excluded from equation (2) and used as an instrument. Concerning the first part of the assumption, Tasciotti and Wagner (2015) have already demonstrated the relationship between urban agriculture and dietary diversity. The second part of the assumption, i.e. the validity of the exclusion restriction, cannot be formally tested and it is left to the judgment of the reader whether the presented argument is considered credible. For completeness we present also the non-instrumented results to highlight further that dietary diversity is indeed enhanced through urban agriculture and it is the dietary diversity achieved by urban farmers that leads to improved anthropometric measurements..

\footnotetext{
4 Detailed summary statistics for these covariates are made available upon request.
} 


\section{Results}

Results are presented in Table 1, columns 1 and 2. Four main results stand out. First, dietary diversity improves child nutritional outcomes as indicated by underweight and stunting respectively. A positive and significant relationship between the total food count and child health indicators arises. Second, the main effect works through better access to animal protein in the form of dairy products, meat, fish and eggs. Third, our indicator for urban agriculture has significant explanatory power for dietary diversity: Practising urban farming and/or keeping livestock leads to the consumption of a greater variety of food items and the health status of urban children living in households engaged in some farming activities significantly improves as a consequence. Fourth, the food category that is least associated with healthy diets, namely sugar, beverages and other products, has no impact on child health. In addition, this food category is not affected by urban agricultural activities as urban farmers do not directly produce its components. This finding further supports the validity of urban agriculture as an instrument as it shows an impact only on foods that are harvested by urban farmers.

We now turn to a detailed discussion of the results. In Table 1, columns 1 and 2 present the results for the different food indicators within six panels. Each panel contains the results from two separate regressions, one for WAZ and one for HAZ. For the sake of brevity we show only the coefficients associated with dietary diversity and urban agriculture. But all regressions contain the full set of covariates (c.f. section 4). Panel A presents the findings associated with the total food count and thus overall dietary diversity. Increasing dietary diversity by an additional food item increases WAZ by 0.18 , which means that the total food count explains $15.77 \%$ of the standard deviation in WAZ. Put differently, we find that increasing the food count from the average of quintile 1 (lowest) to the average of quintile 3 (middle) - a difference of 3.55 items - explains $56.04 \%$ of the standard deviation in WAZ. Importantly, the involvement in agricultural activities identifies the food count at the $1 \%$ significance level suggesting that households engaged in urban agriculture consume 1.87 food items more than urban households that do not practise agricultural activities. The results for the HAZ indicator are similar to those just described. Consumption of an additional food item increases HAZ by 0.17 explaining $12.76 \%$ of the standard deviation in HAZ. In short, children of households engaged in urban agriculture have a more varied diet, which translates into better anthropometric results. 
$<$ Table 1 about here $>$

The positive impact of dietary diversity on child nutritional status stems mainly from the increased intake of milk and dairy products (Table 1, Panel B). Across models, the coefficients associated with the number of milk products are considerably higher compared with the coefficients associated with the total food count; yet, this coefficient estimate needs to be understood relative to the average number of milk products consumed, which is also much lower. All specifications show a positive and highly significant relationship suggesting that regular access to milk products has the potential to offset the observed underweight in the short-term. Again, we find that households practising urban agriculture have more ready access to dairy products. According to our estimates they consume 0.22 more dairy products. Long-term stunting is similarly reduced for children who consume more dairy products. The coefficient estimate is roughly similar to the observed average absolute level of HAZ suggesting that stunting can be prevented if children consume enough milk products. This finding is not surprising and is further supported by the case of rural Ethiopia where it has been shown that cow ownership increases child growth and reduces stunting by raising children's milk consumption (Hoddinott, 2012; Hoddinott et al., 2014).

Next we turn to the impact of the consumption of other animal products such as meat, fish and eggs on child anthropometrics (Table 1, Panel C). Again we find a positive relationship working through the urban agriculture channel. Households engaged in urban agriculture eat 0.4 more animal products including meat and eggs. This translates into a reduction in wasting of 0.35 and a reduction in stunting of 0.34 . Put differently, the consumption of an additional animal product explains $75.24 \%$ of the standard deviation in WAZ and $62.82 \%$ of the standard deviation in HAZ indicating the importance of animalbased proteins for the development of children and demonstrating that urban households engaged in agricultural activities are better equipped to improve the diets of their children.

Similarly positive, albeit smaller, effects are found for the consumption of fresh fruits and vegetables (Table 1, Panel D). The consumption of one more piece of fruit or vegetable explains more than $50 \%$ in the standard deviation of both WAZ and HAZ in the sample. Again the effect works through urban agriculture as can be seen from the first stage results that indicate an additional consumption of 0.44 fruits and/or vegetables for urban households that practise agriculture. 
We also consider the impact on child health, of agricultural staples from the group of rice, grain, tubers, cassava and pulses. For animal products it is reasonable to expect that an increase in the number of food counts improves child nutritional status. Yet the link is less obvious for staple goods such as rice or cassava, which constitute the basis of most meals in Tanzania. We find a positive effect of increasing the number of basic staple goods. However, the effect is not statistically significant. While households practising urban agriculture have better access to rice, grain, tubers, cassava and pulses, this does not result in improved child health. The result is not surprising since this food category describes the major constituents of each and every meal. In fact rice, grain, tubers, cassava and pulses are often the only component of a poor person's meal along with some flavored sauce.

As a last step we test for the impact of sugar, beverages and other products on child health. We find no significant relationship between the consumption of food items in this group and child health. Moreover, the first stage results are invalid, as urban agriculture does not identify the number of food items in this group. This provides a robustness check for our instrument: indicators of urban agriculture identify only food groups that are related to agricultural production. Yet, the urban farmers do not produce sugar, beverages and the other products in this last group of food items. Thus, urban agriculture is not a channel through which access to these products can be increased.

While our focus is on the dietary mechanism working through urban agriculture to improve child health, it might be argued that it suffices to analyse the relationship between dietary diversity and child health directly. Therefore, in Table 1, columns 3 and 4 we also present the non-instrumented results from directly estimating equation (2). As for the main analysis we find a positive relationship between the different food counts and child anthropometrics. However, the estimated coefficients are smaller in size and less likely to be statistically significant. We take this as further evidence that it is indeed the channel of urban agriculture that allows boosting dietary diversity to the extent that it manifests itself in better child health.

In short, we identified urban agriculture as one channel through which dietary diversity can be increased and ultimately improved child health achieved in the cities of developing countries. Our estimates indicate a strong relationship between nutritional diversity and child health through urban agriculture: we interpret the two-stage least squares results as a weighted average of a local average treatment effect implying that our identification strategy reveals the impact of dietary diversity for children living in households 
that engage in urban agriculture (Imbens and Angrist, 1994). Moreover, it shows that the households that are most affected by changes in urban agricultural activities, namely households in the lowest expenditure quintile, are the ones experiencing the greatest effects on dietary diversity. Thus, our results are most informative for urban households, which are by definition vulnerable and use urban agriculture as a coping mechanism. Consequently, we consider the results as an upper bound of the impact of dietary diversity on child nutritional status.

To further verify the robustness of our results we carried out three robustness checks: First we considered only plot sizes smaller than 2 acres; second we excluded animal rearing households from the urban agricultural households; third we did not pose a size restriction on plots and allowed for plots to be located as far away as 100 kilometres.

Our definition of urban agriculture already provides a sample restriction as it excludes both households with distant plots which may be located in rural areas, and large industrial farms. If we focus on farmers with landholdings smaller than 2 acres, our sample size is further reduced; from 624 to 586 observations for the WAZ sample and from 598 to 561 observations for the HAZ sample. This is problematic because it is the poorest households, i.e. those in the lowest expenditure group, that tend to engage most in urban agriculture and tend to have the larger plots. Expenditure groups two and three tend to have smaller plots on average (Online Appendix, Table A1). As a further consequence, the below 2 acres restriction reduces the variation in our urban agriculture indicator. When applying the redefinition of the urban agriculture indicator it is only $13.31 \%$ of the households that engage in urban agriculture, whereas it is $18.59 \%$ in the estimation sample used to produce the main results. Therefore, we are less likely to identify significant effects. Nevertheless, with this smaller sample we identify urban agriculture as a channel for improved dietary diversity (Online Appendix Table A2, columns 1 and 2). The impact of dietary diversity on child health, despite being positive and in line with our main results, is imprecisely estimated.

In addition, we present estimates excluding animal-raising households from the definition of urban farmers. Again, we identify urban agriculture as a channel for increased overall dietary diversity and most prominently and unsurprisingly for increased consumption of fruits and vegetables (Online Appendix Table A2, columns 3 and 4). However, consumption of meat is no longer identified when we exclude animal rearing from our definition of urban agriculture. Furthermore, the impact on child health is again imprecisely estimated. We find similar magnitudes to those in our main estimation sample but the 
coefficients are not statistically significant. We consider this as additional evidence in favour of our definition of urban agriculture that includes animal rearing. Note that our comprehensive classification of urban agriculture is also closer to the definition provided by FAO, which includes the raising of animals.

Finally, we also present a third robustness check where we do not pose a size restriction on plots and allow for plots to be located as far away as 100 kilometres. With this amplified definition of urban agriculture we identify dietary diversity very well (compare first stage regression results of Online Appendix Table A2, columns 5 and 6). Moreover, we also identify the impact of dietary diversity on child health more precisely, mimicking the results obtained for our main estimation sample.

\section{Concluding remarks}

The study highlights that in cities of less developed countries, urban agriculture contributes to increasing the food security of urban dwellers. The presented results are most relevant for small-scale urban farmers with landholdings of up to 5 acres including urban households that raise animals. It is anticipated that farming and keeping livestock in urban areas will gain further recognition for its benefits as more than half of the world population now lives in cities.

We showed the potential of urban agriculture for improving child health. The first result that is demonstrated by our study is that children, especially those living in less wealthy households, benefit from urban agriculture as they experience a significant increase in the availability of dairy food, meat, fish and eggs with visible consequences for their weight and height. This result adds to the exiguous body of evidence, which shows how urban agriculture represents a successful strategy in helping households combat food shocks and provides them with a wide range of food (Zezza and Tasciotti, 2010).

The importance of urban agriculture goes beyond the nutritional and health improvements for the urban residents as it has considerable, but still unrealised, development potential by providing income, shaping the urban environment and buffering negative production shocks (Smit et al., 1996). The importance of urban agriculture clashes with the lack of policies related to land tenure, to access and distribution of public and unused land and with the absence of plans for favouring less advantaged households and women in accessing land (Bryld, 2003). 
Based on our findings about the benefits of urban agriculture for child health we draw the following lesson: central and local governments together with NGOs need to build on the results of a comprehensive research programme to create a new urban food security agenda and formulate country and, if possible, city specific food security programmes that incorporate urban agriculture.

\section{References}

Alderman, H., Behrman, J.R., and Hoddinott, J. (2004). Improving child nutrition for sustainable poverty reduction in Africa (No. 2). International Food Policy Research Institute (IFPRI).

Ambrus, J.L. (2004). Nutrition and infectious diseases in developing countries and problems of acquired immunodeficiency syndrome. Exp Biol Med, 229: 464-72.

Arimond, M. and Ruel, M. T. (2002). Progress in Developing an Infant and Child Feeding Index: an Example Using the Ethiopia Demographic and Health Survey 2000. Food Consumption and Nutrition Division Discussion Paper 143. International Food Policy Research Institute, Washington, DC.

Arimond, M., and Ruel, M. T. (2004). Dietary diversity is associated with child nutritional status: evidence from 11 demographic and health surveys. The Journal of nutrition, 134(10), 2579-2585.

Armar-Klemesu, M. (2001). Urban agriculture and food security, nutrition and health. In: Growing Cities, Growing Food: Urban Agriculture on the Policy Agenda. A Reader on Urban Agriculture. Bonn, Germany.

Black, R. E., Morris, S.S. and Bryce, J. (2003). Where and why are 10 million children dying every year? Lancet, 361: 2226-34.

Brock, B. and Foeken, D. (2006). Urban horticulture for a better environment: a case study of Cotonou, Benin. Habitat International, 30(3): 558-578.

Bryce, J., Coitinho, D., Darnton-Hill, I., Pelletier, D. and Pinstrup-Andersen, P. (2008). Maternal and child undernutrition: effective action at national level, The Lancet, 371: 510526.

Bryld, E. (2003). Potentials, problems, and policy implications for urban agriculture in developing countries. Agriculture and Human Values, 20(1): 79-86.

Charlemaigne V. C. and Gauthier, A. H. (2009). The social determinants of child health: variations across health outcomes -- a population-based cross-sectional analysis. BMC Pediatrics, 9(1): 1-12.

Crush, J. S. and Frayne, G. B. (2011). Urban food insecurity and the new international food security agenda. Development Southern Africa, 28(4): 527-544. 
De Onis, M., (2006). WHO child growth standards: Length/height-for-age, weight-for-age, weight-for-length, weight-for-height and body mass index-for-age: Methods and development. Technical Report. World Health Organization, Geneva.

De Onis, M. and Blössner, M. (2003). The world health organization global database on child growth and malnutrition: methodology and applications. International Epidemiological Association, 32: 518-526.

Djurfeldt, A.A. (2015). Urbanization and linkages to smallholder farming in sub-Saharan Africa: Implications for food security. Global Food Security, 4: 1-7.

Drechsel, P. and Kunze, D. (2001). Waste composting for urban and peri-urban agriculture: closing the rural-urban nutrient cycle in sub-saharan Africa. CABI Publishing, Wallingford and New York, International Water Management Institute, Colombo, Sri Lanka and the Food and Agriculture Organization of the United Nations, Rome.

Ellis F., and Sumberg J. (1998). Food production, urban areas and policy responses. Food Policy, 26: 213-225.

FANTA (2006). Developing and Validating Simple Indicators of Dietary Quality and Energy Intake of Infants and Young Children in Developing Countries: Summary of findings from analysis of 10 data sets. Working Group on Infant and Young Child Feeding Indicators. Food and Nutrition Technical Assistance (FANTA) Project, Academy for Educational Development (AED), Washington, D.C.

FAO (2014). The state of food insecurity in the world. Strengthening the enabling environment for food security and nutrition. Food and Agriculture Organization of the United Nations, Rome, Italy.

Friel, J. K., Aziz, K., Andrews, W. L., Harding, S. V. , Courage, M. L. and Adams, R. J. (2003). A double-masked, randomized control trial of iron supplementation in early infancy in healthy term breast-fed infants. Journal of Pediatrics, 143(5): 582-586.

Garrett, J. L. and Ruel, M. T. (2005). Stunted child-overweight mother pairs: prevalence and association with economic development and urbanization. Food and Nutrition Bulletin, 26(2): 209-221.

Glewwe, P. and King, E. (2001). The impact of early Child nutritional status on cognitive development: Does the timing of malnutrition matter? World Bank Economic Review, 15(1): 81-113.

Glewwe, P., Jacoby, H.G. and King, E.M. (2001). Early childhood nutrition and academic achievement: a longitudinal analysis. Journal of Public Economics, 81(3): 345-368.

Grantham-McGregor S. and Ani, C. (2001). A review of studies on the effect of iron deficiency on cognitive development in children. Journal of Nutrition, 131(2S-2): 649S-666S.

Hoddinott, J. (2012). Agriculture, health, and nutrition: Toward conceptualizing the linkages. In: S. Fan and R. Pandya-Lorch (eds.) Reshaping Agriculture for Nutrition and Health. Washington DC: International Food Policy Research Institute. 
Hoddinott, J., Headey, D. and Mekdim, D. (2014). Cows, missing milk markets and nutrition in rural Ethiopia. Journal of Development Studies, 51(8): 958-975.

Imbens, G. and Angrist, J. (1994). Identification and estimation of local average treatment effects. Econometrica, 62 (2): 467-476.

Kant, A. K. (1996). Indexes of overall diet quality: a review. J. Am. Diet. Assoc, 96: 785791.

Kant, A. K., Schatzkin, A. and Ziegler, R. G. (1995). Dietary diversity and subsequent cause-specific mortality in the NHANES I epidemiologic follow-up study. Journal of the American College of Nutrition, 14(3): 233-238.

Liu, L., Oza, S., Hogan, D., Perin, J., Rudan, I., Lawn, J. E. and Black, R. E. (2015). Global, regional, and national causes of child mortality in 2000-13, with projections to inform post2015 priorities: an updated systematic analysis. The Lancet, 385(9966): 430-440.

Lozoff, B., De Andraca, I., Castillo, M., Smith, J. B., Walter, T. and Pino, P. (2003). Behavioral and developmental effects of preventing iron-deficiency anemia in healthy fullterm infants. Pediatrics, 112(4): 846-854.

Maltsoglou, I., Dawe, D., \& Tasciotti, L. (2010). Household level impacts of increasing food prices in Cambodia. Food and Agriculture Organization of the United Nations (FAO).

Marmot, M., Friel, S., Bell, R., Houweling, T. and Taylor, S. (2008). Closing the gap in a generation: health equity through action on the social determinants of health. The Lancet, 372(9650): 1661-1669.

Mbaye A. and Moustier P. (2000). Market-oriented urban agricultural production in Dakar, in: Bakker N., Dubbeling M., Gündel S., Sabel-Koschella U., Zeeuw H. de (Eds.), Growing cities, growing food: Urban agriculture on the policy agenda. A reader on urban agriculture, DSE/ETC, Feldafing, Allemagne, UN2006, pp. 235-257.

Mendez, M.A. and Adair, L.S. 1999. Severity and Timing of Stunting in the First Two Years of Life Affect Performance on Cognitive Tests in Late Childhood. Journal of Nutrition, 129(8): 1555-1562.

Mougeot, L.J.A. (2005) Urban agriculture and the millennium development goals. In: Mougeot L.J.A. (ed) AGROPOLIS. The social, political and environmental dimensions of urban agriculture. Earthscan, London.

Moustier P. and Danso G. (2006). Local economic development and marketing of urban produced food, in: van Veenhuisen René (Ed.), Cities farming for the future: Urban agriculture for green and productive cities, RUAF Foundation, International Institute of Rural Reconstruction, International Development Research Centre, PO Box 8500, Ottawa, ON K1G 3H9, Canada, pp. 173-208.

Müller O., Garenne, M., Reitmaier, P., van Zweeden, A., Kouyate, B. and Becher H. (2003). Effect of zinc supplementation on growth in West African children: a randomized doubleblind placebo-controlled trial in rural Burkina Faso. Int J Epidemiol, 32: 1098-102. 
Müller, O. and Krawinkel, M. (2005). Malnutrition and health in developing countries. CMAJ, 173(3): 279-286.

Nugent, R. (2000). The impact of urban agriculture on the household and local economies. In: Bakker, N., Dubbeling, M., Guendel, S., Sabel-Koschella, U., de Zeeuw, H. (Eds.), Growing Cities, Growing Food. Urban Agriculture on the Policy Agenda. Deutsche Stiftung für internationale Entwicklung (DSE), Feldafing (Germany), pp. 67-98.

Onyango, A., Koski, K. G. and Tucker, K. L. (1998). Food diversity versus breastfeeding choice in determining anthropometric status in rural Kenyan toddlers. Int. J. Epidemiol, 27: 484-489.

Owuor, S.O. and Foeken, D. (2006). Surviving in the neighbourhoods of Nakuru town, Kenya. In: Konings, P., Foeken, D. (Eds.), Crisis and Creativity: Exploring the Wealth of the African Neighbourhood. Brill, Leiden, pp. 22-45.

Pellegrini, L. and Tasciotti, L. (2014). Crop diversification, dietary diversity and agricultural income: empirical evidence from eight developing countries. Canadian Journal of Development Studies/Revue canadienne d'études du développement, 35(2): 211-227.

Potts, D. (1997). Urban lives: adopting new strategies and adapting rural links. In: Rakodi, C. (Ed.), The Urban Challenge in Africa: Growth and Management of the Large Cities. United Nations University Press, Tokyo/New York, pp. 447-494.

Potutan, G. E., Schnitzler, W. H., Amado J. M., Janubas, L. G. and Holmer, R. J. (2000). Urban agriculture in Cagayan de Oro: a favourable response of city government and NGOs. Unpublished manuscript.

Rakodi, C. (2002). A livelihoods approach - conceptual issues and definitions. In: Rakodi, C., Lloyd-Jones, T. (Eds.), Urban Livelihoods: A People-Centred Approach to Reducing Poverty. Earthscan, London, pp. 3-22.

Rakodi, C. and Lloyds-Jones, T. (2002). Urban Livelihoods: A People-Centred Approach to Reducing Poverty. Earthscan, London.

Ravallion, M., Chen, S. and Sangraula, P. (2007). New Evidence on the Urbanization of Global Poverty. Population and Development Review, 33(4): 667-701.

Ronnenberg, A. G., Wood, R. J., Wang, X., Xing, H., Chen, C., Chen, D., Guang, W., Huang, A., Wang, L. and $\mathrm{Xu}, \mathrm{X}$. (2004). Preconception hemoglobin and ferritin concentrations are associated with pregnancy outcome in a prospective cohort of Chinese women. Journal of Nutrition, 134(10): 2586-2591.

Ruel, M.T. (2003). Operationalizing dietary diversity: A review of measurement issues and research priorities. Journal of Nutrition, 133(11): 3911S-3926S.

Ruel, M. T., Garrett, J. L., Morris, S. S., Maxwell, D., Oshaug, A., Engle, P., Menon, P., Slack, A. T. and Haddad, L. J. (1998). Urban challenges to food and nutrition security. FCND discussion papers 51, International Food Policy Research Institute (IFPRI). 
Savy, M., Martin-Prével, Y., Traissac, P., Eymard-Duvernay, S. and Delpeuch, F. (2006). Dietary Diversity Scores and Nutritional Status of Women Change during the Seasonal Food Shortage in Rural Burkina Faso. J. Nutr, 136(10): 2625-2632.

Shackleton C.M.M., Pasquini M.W. and Drescher A.W. (2009). African indigenous vegetables in urban agriculture. Earthscan, London. ISBN 978-18440-771-5-1.

Smit, J., Nasr, J. and Ratta, A. (1996). Urban agriculture: food, jobs and sustainable cities. New York, USA.

Taren, D. and Chen, J. (1993). A positive association between extended breast-feeding and nutritional status in rural Hubei Province, People's Republic of China. Am. J. Clin. Nutr, 58: 862-867.

Tasciotti, L. and Wagner. N. (2015). Urban Agriculture and Dietary Diversity: Empirical Evidence from Tanzania. European Journal of Development Research, 27(5): 631-649.

UNICEF (2010). Causes and most vulnerable to under-nutrition-UNICEF conceptual framework. New York: UNICEF. Available at: http://www.unicef.org/nutrition/training/2.5/4.html.

van Veenhuizen, R. (2006). Cities farming for the future. Urban agriculture for sustainable cities. RUAF Foundation, IDRC and IIRR.

Wagner, N. and Rieger, M. (2015). Child Health, its Dynamic Interaction with Nutrition and Health Memory - Evidence from Senegal. Economics and Human Biology, 16: 135-145.

World Bank (2007). Global Economic Prospects 2007: Managing the Next Wave of Globalization. Washington.

Zezza, A. and Tasciotti, L. (2010). Urban agriculture, poverty, and food security: Empirical evidence from a sample of developing countries. Food policy, 35(4): 265-273. 


\section{Tables and figures}

Table 1: Results for the relationship between child health and dietary diversity

\begin{tabular}{|c|c|c|c|c|}
\hline & \multicolumn{2}{|c|}{ 2SLS estimates } & \multicolumn{2}{|c|}{ OLS estimates } \\
\hline & WAZ & $\underline{\text { HAZ }}$ & WAZ & $\underline{\text { HAZ }}$ \\
\hline \multicolumn{5}{|l|}{ Panel A } \\
\hline Total food count & $\begin{array}{c}0.183^{* *} \\
(0.082)\end{array}$ & $\begin{array}{l}0.172^{* *} \\
(0.084)\end{array}$ & $\begin{array}{c}0.017 \\
(0.012)\end{array}$ & $\begin{array}{l}0.031^{* *} \\
(0.012)\end{array}$ \\
\hline \multicolumn{5}{|l|}{ First stage } \\
\hline Urban agriculture & $\begin{array}{c}1.867^{* * *} \\
(0.637)\end{array}$ & $\begin{array}{c}1.889^{* * *} \\
(0.624)\end{array}$ & - & - \\
\hline \multicolumn{5}{|l|}{ Panel B } \\
\hline Milk products (\#) & $\begin{array}{l}1.587^{* *} \\
(0.727)\end{array}$ & $\begin{array}{c}1.556^{*} \\
(0.827)\end{array}$ & $\begin{array}{c}0.115 \\
(0.095)\end{array}$ & $\begin{array}{c}0.036 \\
(0.100)\end{array}$ \\
\hline \multicolumn{5}{|l|}{ First stage } \\
\hline Urban agriculture & $\begin{array}{l}0.215^{* *} \\
(0.083)\end{array}$ & $\begin{array}{l}0.208^{* *} \\
(0.084)\end{array}$ & - & - \\
\hline \multicolumn{5}{|l|}{ Panel C } \\
\hline Meat, fish, eggs (\#) & $\begin{array}{l}0.871^{* *} \\
(0.435)\end{array}$ & $\begin{array}{c}0.845^{*} \\
(0.472)\end{array}$ & $\begin{array}{c}0.043 \\
(0.049)\end{array}$ & $\begin{array}{c}0.080 \\
(0.050)\end{array}$ \\
\hline \multicolumn{5}{|l|}{ First stage } \\
\hline Urban agriculture & $\begin{array}{l}0.391^{* *} \\
(0.154)\end{array}$ & $\begin{array}{c}0.384^{* *} \\
(0.155)\end{array}$ & - & - \\
\hline \multicolumn{5}{|l|}{ Panel D } \\
\hline Fruits and vegetables (\#) & $\begin{array}{c}0.773^{*} \\
(0.405)\end{array}$ & $\begin{array}{c}0.750^{*} \\
(0.418)\end{array}$ & $\begin{array}{c}0.035 \\
(0.040)\end{array}$ & $\begin{array}{c}0.043 \\
(0.044)\end{array}$ \\
\hline \multicolumn{5}{|l|}{ First stage } \\
\hline Urban agriculture & $\begin{array}{l}0.441^{* *} \\
(0.188)\end{array}$ & $\begin{array}{l}0.432^{* *} \\
(0.186)\end{array}$ & - & - \\
\hline \multirow{2}{*}{$\begin{array}{l}\text { Rice, grain, tuber, pulses } \\
\text { (\#) }\end{array}$} & 0.681 & 0.620 & & $0.051^{* *}$ \\
\hline & $(0.456)$ & (0.408) & $(0.021)$ & $(0.022)$ \\
\hline Urban agriculture & $\begin{array}{c}0.501^{*} \\
(0.298) \\
\end{array}$ & $\begin{array}{c}0.523^{*} \\
(0.286) \\
\end{array}$ & - & - \\
\hline \multicolumn{5}{|l|}{ Panel F } \\
\hline Sugar and beverages (\#) & $\begin{array}{c}1.651 \\
(1.197)\end{array}$ & $\begin{array}{c}1.512 \\
(1.099)\end{array}$ & $\begin{array}{c}0.010 \\
(0.041)\end{array}$ & $\begin{array}{c}0.083^{*} \\
(0.043)\end{array}$ \\
\hline \multicolumn{5}{|l|}{ First stage } \\
\hline Urban agriculture & $\begin{array}{c}0.206 \\
(0.148)\end{array}$ & $\begin{array}{c}0.214 \\
(0.147)\end{array}$ & - & - \\
\hline
\end{tabular}

Notes: The WAZ models have 624 observations; the HAZ models have 598 observations. The first pair of columns present 2SLS results, the second pair of columns OLS results. All models contain the following set of control variables that are not reported for the sake of brevity: (i) household demographics such as size, share of children below 5 years, share of women of working age, whether the household always lived at the current place of residence (to capture continuity) and indicator variables for the household expenditure quintiles, (ii) child characteristics such as age and gender, (iii) maternal characteristics such as age, education marital status and indicator variables for holding a government job, working for the private sector or being self-employed, (iv) paternal characteristics such as age, education and indicator variables for holding a government job, working for the private sector or being self-employed, (iv) food processing variables such as the availability of a refrigerator and an indicator variable for high quality processing equipment in the form of gas and electric stoves. The date of the survey is also accounted for. The first stage contains all control variables including the indicator variable 'urban agriculture'. Only the coefficient associated with the latter is presented. Clustered standard errors are in parentheses. $* /{ }^{* *} /{ }^{* * *}$ indicates $\mathrm{p}<0.10 / 0.05 / 0.01$, respectively.

Source: TZNPS 2008-2009 and 2010-2011. 
Figure 1. Share of urban households engaged in agricultural activities, by expenditure quintile

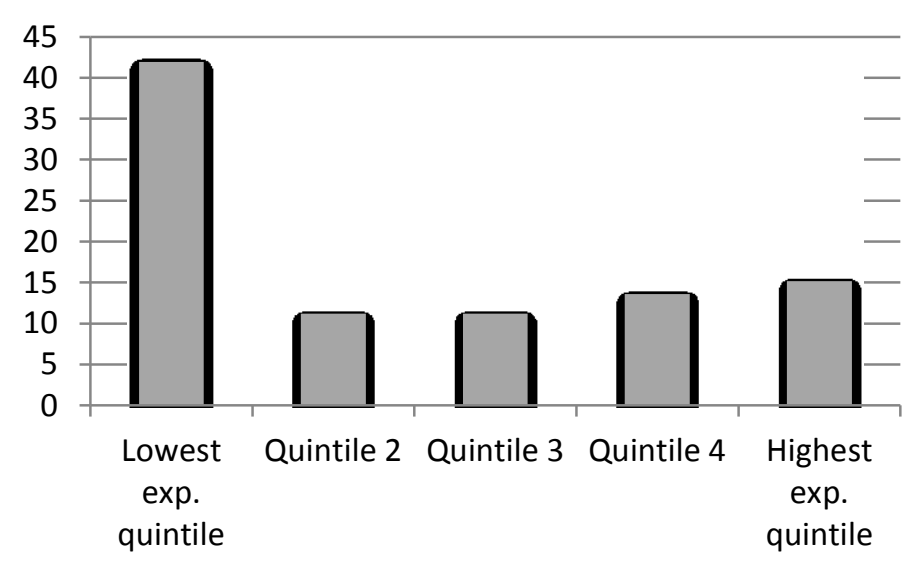

Notes: The vertical axis is measured in percentage.

Source: TZNPS 2008-2009 and 2010-2011. 